\title{
SCOPOSCARTULA YOUNG: DESCRIÇÕES DE UMA ESPÉCIE NOVA E DA FÊMEA DE S. FLAVOVITTATA MEJDALANI, E REDESCRIÇÃO DE S. CONCINNA (PERTY) COMB,N. (HOMOPTERA, CICADELLIDAE, CICADELLINI)
}

\author{
Rodney R. Cavichioli ${ }^{2}$ \\ Gabriel L. Mejdalani ${ }^{3}$
}

\begin{abstract}
SCOPOSCARTULA YOUNG: DESCRIPTIONS OF A NEW SPECIES AND OF THE FEMALE of $S$. FlavovitTata Mejdalani and REDESCRIPTION OF $S$. CONCINNA (PERTY) COMB.N. (Homoptera, CiCADEllidaE, CiCADELlinAE). Scoposcartula tobiasi sp.n. is described from the states of Rio de Janeiro, Minas Gerais, and São Paulo, southeastern Brazil. The previously unknown female of Scoposcartula flavovittata Mejdalani, 1992 is described from the state of Rio de Janeiro. Tettigonia concinna Perty, 1833 is transferred to Scoposcartula Young, 1977 based on a male from the state of Bahia, northeastern Brazil.

KEY WORDS. Cicadellidae, Scoposcartula, new species, taxonomic notes, Brazil
\end{abstract}

Scoposcartula Young, 1977 - espécie-tipo: S. oculata (Signoret, 1853) possui dez espécies descritas, todas com registros no Brasil (YoUNG 1977; ZANOL \& MENEZES 1982; MEJDALANI 1992). Esse gênero apresenta espécies de grande porte e robustas, variando entre 8 e $13 \mathrm{~mm}$ de comprimento. YoUNG (1977: 613) incluiu Scoposcartula no grupo genérico Oragua, juntamente com outros sete gêneros (Oragua Melichar, 1926; Acrulogonia Young,1977; Tubiga Young, 1977; Selvitsa Young, 1977; Schildola Young, 1977; Jakrama Young, 1977 e Trachygonalia Young, 1977). Scoposcartula destingue-se pela seguinte combinação de caracteres: (1) ocelos situados atrás da linha imaginária que tangencia os bordos anteriores dos olhos; (2) pronoto mais largo que a cabeça; (3) pigóforo sem processos; (4) paráfise presente.

No presente trabalho, descreve-se uma nova espécie de Scoposcartula ( $S$. tobiasi n.sp.) proveniente da Serra da Mantiqueira, sudeste do Brasil. A fêmea de S. flavovittata Mejdalani, 1922 é pela primeira vez descrita, com base em um único espécime coletado na localidade-tipo da espécie (Maricá, Rio de Janeiro). Tettigonia concinna Perty, 1833, uma espécie considerada de posição incerta por YounG (1977), é transferida para Scoposcartula, a partir do estudo de um macho procedente da Bahia.

1) Contribuição número 982 do Departamento de Zoologia, Universidade Federal do Paraná.

2) Departamento de Zoologia, Universidade Federal do Paraná. Caixa Postal 19020, 81531-990 Curitiba, Paraná, Brasil. Pesquisador do CNPq.

3) Departamento de Zoologia, Universidade Federal do Rio de Janeiro. Caixa Postal 68044 , 21944-970 Rio de Janeiro, Rio de Janeiro, Brasil. 
As seguintes siglas designam as coleções de onde são provenientes os espécimens utilizados neste estudo: (MNRJ) Museu Nacional, Universidade Federal do Rio de Janeiro; (MZSP) Museu de Zoologia, Universidade de São Paulo; (DZUP) Coleção de Entomologia Pe. J.S. Moure, Departamento de Zoologia, Universidade Federal do Paraná; (UFRJ) Departamento de Zoologia, Universidade Federal do Rio de Janeiro; (BMNH) The Natural History Museum, Londres, Inglaterra.

\section{Scoposcartula tobiasi sp.n.}

Figs 1-10

Holótipo macho. BRAsIL, Rio de Janeiro: Garganta do Registro (divisa Rio de Janeiro-Minas Gerais), 30-IX-1993, G. Mejdalani leg. (DZUP). Alótipo: BRASIL, Minas Gerais: Delfim Moreira (1100m), II-1972, F.M. Oliveira leg. (BMNH). Parátipos: BRASIL, Minas Gerais: Delfim Moreira (1100m), 2 machos e 1 fềmea, II-1972, F.M. Oliveiro leg. (BMNH); Itamonte (Serra Negra), 2 machos 2-X-1993, G. Mejdalani leg. (DZUP); 1 macho, mesmos dados dos espécimes precedentes (UFRJ); Itamonte (Morro Cavado), 1 fêmea 3-X-1993, A.C. Alves leg. (UFRJ). Rio de Janeiro: Garganta do Registro (Divisa Rio de Janeiro-Minas Gerais), 3 machos e 1 fêmea 30-IX-1993, A.C. Alves leg. (DZUP); Itatiaia, (2000m), 1 fêmea I-1957, U. Barth leg. (MNRJ). Parque Nacional de Itatiaia (Divisa Rio de Janeiro-Minas Gerais, próximo ao Brejo da Lapa), 1 macho e 1 fêmea 16-X-1993, G. Mejdalani leg. (UFRJ); Parque Nacional de Itatiaia, Abrigo Macieiras, 2 macho 02-VIII-1986, R.L. Cruz leg. (DZUP); São Paulo: Campos do Jordão (1600m), 1 fềmea III-1945, Wygodzinsky leg. (MNRJ); 1 fêmea e 2 machos [um deles determinado por D.A. Young como Scoposcartula limitata (Signoret, 1853)], XII-1955, J. Lane leg. (MZSP).

Diagnose. Coloração geral castanho-clara a escura; terço basal das tégminas com uma curta faixa amarela longitudinal entre as veias Setor e Média; paráfise bicurvada, com ápice agudo.

Descrição. Holótipo macho. Medidas (em milímetros), Holótipo/Alótipo: comprimento total: $11,52 / 11,60$; comprimento mediano da cabeça: $0,80 / 0,88$; distância transocular: 2,52/2,76; distância interocular: 1,64/1,80; comprimento mediano do pronoto: $1,56 / 1,60$; distância entre os úmeros: $2,72 / 2,84$; comprimento das tégminas: 9,64/9,60 ; largura máxima das tégminas: 2,52/2,32. Comprimento total médio dos machos: 11,49; das fêmeas: 11,52. Cabeça, em vista dorsal, levemente pronunciada, com comprimento mediano quase $1 / 3$ da distância transocular e aproximadamente $1 / 4$ a 5/9 da interocular; margem anterior arredondada, sem carena na transição entre a coroa e a face; ocelos situados atrás da linha imaginária que tangencia os bordos anteriores dos olhos e adjacentes às fóveas entre os olhos e ocelos; superficie dorsal finamente pontuada; lóbulos suprantenais, em vista dorsal, não proeminentes, em vista lateral, oblíquos e não carenados; clípeo mais longo do que sua largura basal, de perfil, convexo, com impressões musculares nítidas; sutura transclipeal completa; anteclípeo levemente abaulado medianamente, de perfil, contínuo ao clípeo e com uma leve angulação na porção mediana, ápice 


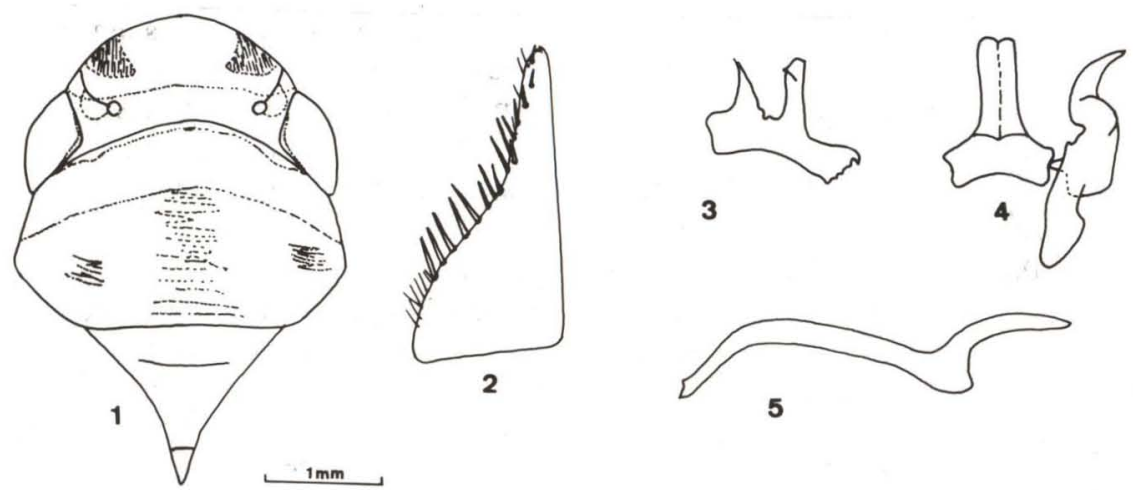

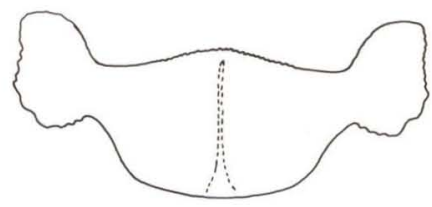

6
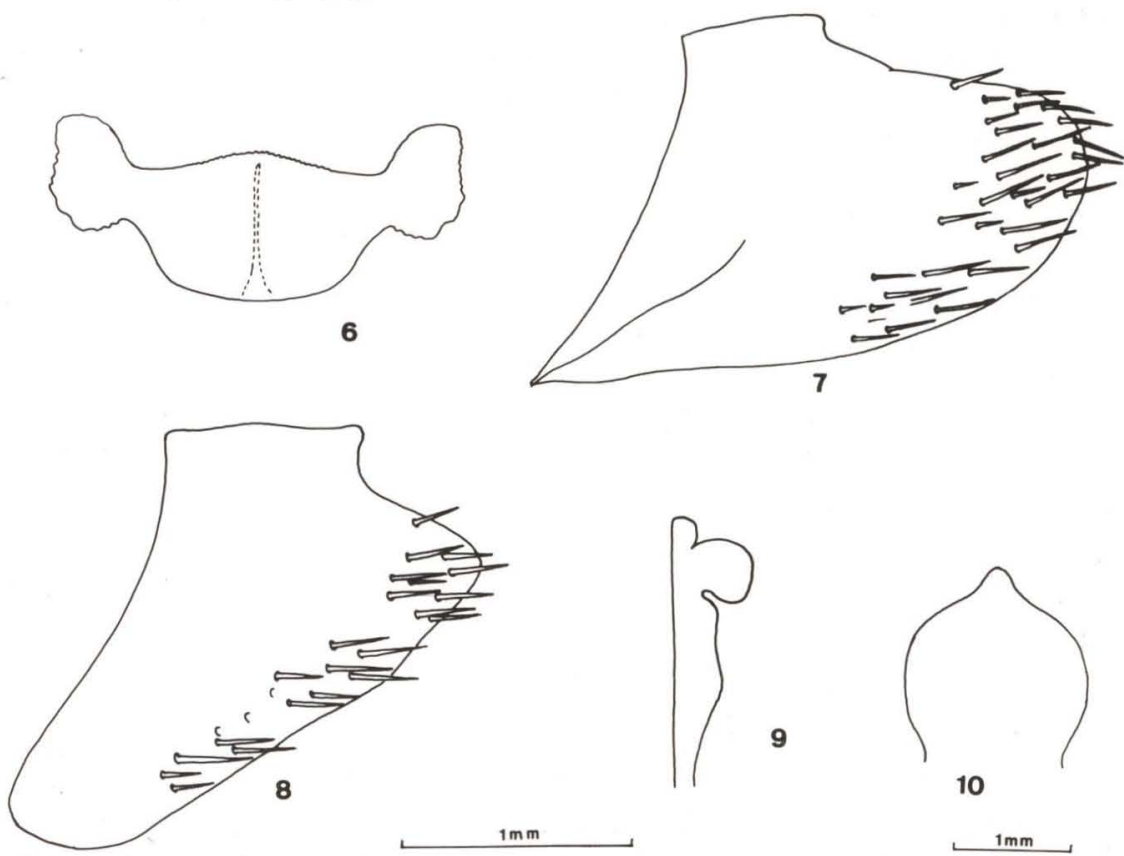

Figs 1-10. Scoposcartula tobiasi sp.n.. (1) Cabeça, pronoto e escutelo (holótipo), em vista lateral. (2-10) Parátipos. (2) Placa subgenital, em vista ventral; (3) edeago, em vista lateral; (4) conetivo e parâmero, em vista dorsal; (5) paráfise, em vista lateral; (6) câmara genital da fêmea: (7) pigóforo do macho, em vista lateral; (8) pigóforo da fêmea, em vista lateral; (9) base da segunda valva do ovipositor, em vista ventral; (10) VII esternito, em vista ventral.

convexo. Pronoto levemente mais largo que a cabeça, comprimento mediano aproximadamente $3 / 5$ a 5/8 da largura entre os úmeros; margens laterais convergentes anteriormente e a posterior mais ou menos retilínea, superfície dorsal com estrias do terço anterior à margem posterior; carena notopleural completa; escutelo tão 
largo basalmente quanto longo, sem estrias. Tégminas quatro vezes mais longa do que largas, venação distinta, finamente pontuadas, exceto o ápice membranoso; com quatro células apicais, sendo a base da quarta mais proximal do que as da segunda e terceira, sem veias extranumerárias e plexo de veias; com três células anteapicais, sendo a mediana aberta basalmente. Asas posteriores quase tão longas quanto as anteriores e com $\mathrm{S}_{1+2}$ incompleta.

Pigóforo mais longo do que sua largura basal, margem posterior convexa, sem processos, com macrocerdas distribuídas no terço posterior; placa subgenital triangular, bipartida, com uma fileira de macrocerdas nas margens laterais; parâmeros levemente robustos, não atingindo o ápice do conetivo, abaulados medianamente e com os ápices voltados para fora e pontiagudos; conetivo em forma de "T" e com uma leve carena mediana; edeago curto, voltado para cima, formando um ângulo de $90^{\circ}$ com a sua base, ápice com um pequeno processo voltado para trás, base do edeago com um processo voltado para baixo e para trás, tão longo quanto o edeago, alargado e denteado apicalmente; paráfise não ramificada, bicurva e com ápice pontiagudo, voltado para cima.

Coloração. Coloração geral acastanhada. Cabeça com manchas pretas, na margem posterior entre os olhos e atrás dos ocelos, e um par sobre as impressões musculares. Pronoto preto, com uma faixa transversa amarelo-pálida no terço anterior. Tégminas com uma faixa longitudinal mediana amarela entre as veias Setor e Média e com alguns pontos arredondados amarelo-acastanhados na base da região costal e sutura claval.

Fêmea. Idêntica ao macho, levemente maior. Pigóforo mais largo basalmente do que longo, levemente obtuso na margem apico-dorsal, com macrocerdas distribuidas ao longo do terço apical; VII esternito mais longo do que largo, margem apical com uma projeção obtusa medianamente; câmara genital larga, com dois lobos situados nas laterais; primeira valva do ovipositor bilobada, sendo o lobo lateral bem pronunciado e o basal estreito.

Discussão. Utilizando-se a chave de identificação de YouNG (1977), Scoposcartula tobiasi sp.n. fica muito próxima de $S$. limitata (Signoret, 1853), principalmente no que diz respeito a coloração e morfologia da genitália masculina. Entretanto, a nova espécie, é mais escura e apresenta uma faixa longitudinal amarela nas tégminas, enquanto que em $S$. limitata é transversal. O conetivo é mais curto na espécie nova e a projeção anteapical da paráfise é voltada para cima e arredondada. Em S. limitata, a projeção anteapical é voltada para baixo e aproximadamente triangular. O esternito VII feminino possui uma projeção apical obtusa em S. tobiasi sp.n. e, em S. limitata é aguda.

Scoposcartula tobiasi é uma espécie comum na Serra da Mantiqueira. No Parque Nacional de Itatiaia, essa espécie foi coletada desde a mata altitudinal inferior (aproximadamente $1.500 \mathrm{~m}$ ) até áreas intermediárias entre a mata altitudinal superior e os campos de altitude (aproximadamente $2.100 \mathrm{~m}$ ). O nome da espécie é uma homenagem a Tobias de Sampaio Cavichioli, filho do primeiro aut^r. 


\section{Scoposcartula concinna (Perty, 1833) comb.n.}

Figs 11-21

Tettigonia concinna Perty, 1833: 180. - Signoret, 1853: 335. - Blanchard, 1840: 191. - Walker, 1858: 201. - Young, 1977: 1100

Cardioscarta concinna; Melichar, 1932: 335

Poeciloscarta concinna; Metcalf, 1965: 63

Material examinado. BrasiL, Bahia: Ilhéus, 1 macho VII-1965, S. Laroca leg., (DZUP); 1 fêmea localidade desconhecida [etiqueta com $\mathrm{n}^{\circ}$ 684]. (DZUP).

Diagnose. Coloração geral vermelho-tijolo, tégminas pretas com uma mancha arredondada na base das células anteapicais. Edeago muito curto, com processo base-ventral.

Descrição. Macho. Medidas (média em milímetros), fêmea/macho -comprimento total: 12,68/12,00; comprimento mediano da cabeça: 1,04/1,08; distância transocular: 2,76/2,64; distância interocular: 1,76/1,72; comprimento mediano do pronoto: $1,92 / 1,80$; distância entre os úmeros: $2,88 / 2,84$; comprimento das tégminas: $10,32 / 9,68$; largura máxima das tégminas: 2,28/2,24. Cabeça, em vista dorsal, levemente pronunciada, com comprimento mediano quase $1 / 3$ da distância transocular e 1/2 da interocular; margem anterior arredondada, sem carena na transição entre a coroa e a face, sem esculturações; ocelos situados levemente atrás da linha imaginária que tangencia os bordos anteriores dos olhos e adjacentes às fóveas entre os olhos e ocelos; superfície dorsal finamente pontuada; lóbulos suprantenais, em vista dorsal, não proeminentes, em vista lateral, oblíquos e com uma leve carena; clípeo mais longo do que sua largura basal, de perfil, convexo, com impressões musculares nítidas; sutura transclipeal completa; anteclípeo levemente abaulado medianamente, de perfil, contínuo ao clípeo e com uma leve angulação na porção mediana, ápice convexo. Pronoto levemente mais largo que a cabeça, comprimento mediano quase $2 / 3$ da largura entre os úmeros; margens laterais convergentes anteriormente e a posterior mais ou menos retilínea, superfície dorsal com estrias do terço anterior à margem posterior; carena notopleural completa; escutelo tão largo basalmente quanto longo, sem estrias. Tégminas quatro vezes mais longas do que largas, venação pouco distintas; com quatro células apicais, sendo a base da quarta mais proximal do que a terceira, sem veias extranumerárias e plexo de veias; com três células anteapicais fechadas. Asas posteriores quase tão longas quanto as anteriores e com $\mathrm{S}_{1+2}$ incompleta.

Pigóforo levemente mais longo do que sua largura basal, margem apical levemente obtusa, sem processos, com macrocerdas distribuídas no terço posterior; placa subgenital triangular, bipartida, com macrocerdas nas margens laterais; parâmeros robustos, quase atingindo o ápice do conetivo, abaulados medianamente e com os ápices voltados para fora e pontiagudos; conetivo em forma de $\mathrm{T}$ e com uma leve carena mediana; edeago muito curto, tão largo quanto longo, voltado para trás, com processo base-ventral, três vezes e meia o comprimento do edeago, paráfise sem ramificação, longa, assimétrica com ápice agudo.

Coloração. Cabeça, tórax e pernas de coloração geral vermelho-tijolo. Cabeça, em vista dorsal, com uma faixa transversa preta no ápice, prolongando-se em 


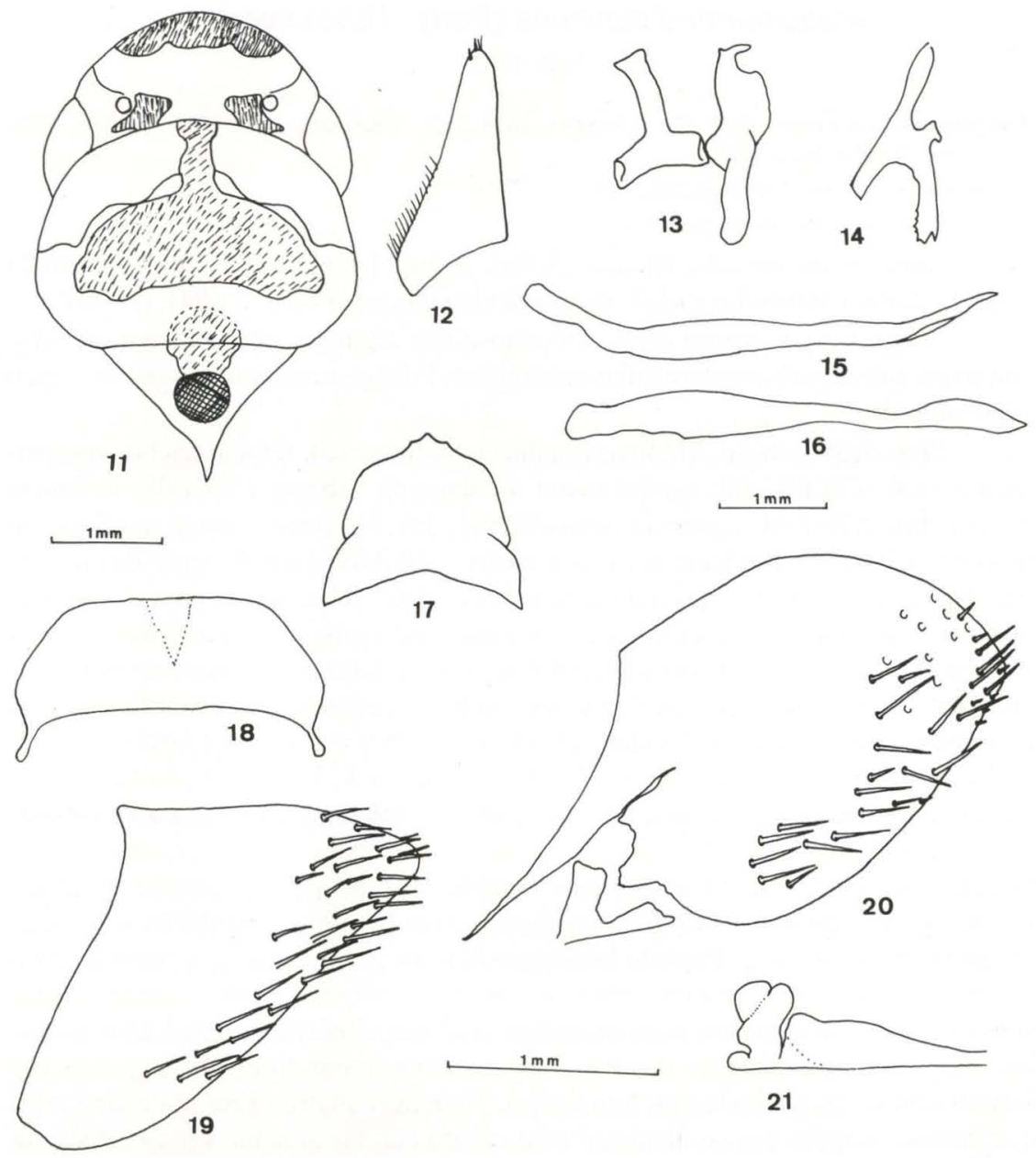

Figs 11-21. Scoposcartula concinna (Perty, 1833). (11) Cabeça, pronoto e escutelo, em vista lateral; (12) placa subgenital, em vista ventral; (13) conetivo e parâmero, em vista dorsal; (14) edeago, em vista lateral; (15) Paráfise, em vista lateral; (16) paráfise, em vista dorsal; (17) VII esternito, em vista ventral; (18) câmara genital da fêmea, em vista dorsal; (19) pigóforo da fêmea, em vista lateral; (20) pigóforo do macho, em vista lateral; (21) base da segunda valva do ovipositor, em vista ventral.

duas estriais ao longo das margens laterais do clípeo, formando, em vista frontal, um $P i(\pi)$; duas manchas pretas, mais ou menos triangulares, adjacentes aos ocelos. Pronoto com uma mancha preta, em forma de um $\mathrm{T}$ invertido, com o ramo transverso mais ou menos retangular, ocupando $1 / 3$ da área central do pronoto. Escutelo com uma mancha arredondada na sua base, de posição mediana, sendo parte encoberta pelo pronoto. Tégminas de coloração geral preta, com ápice esfumaçado, tendo na 
região mediana junto à base das células anteapicais uma mancha amarela de forma mais ou menos arredondada.

Fêmea. Idêntica ao macho. Pigóforo tão longo quanto largo, com a margem apico-dorsal afilada, com macrocerdas distribuidas ao longo da margem apical; VII esternito subquadrangular com a margem apical mais ou menos reta e medianamente com uma projeção pontiaguda; câmara genital mais ou menos retangular e esclerosada, exceto na região mediana. Primeira valva do ovipositor com lobo na margem externa, próximo à base e com projeção digitiforme na base.

Discussão. A identificação de Tettigonia concinna foi baseada na descrição e ilustração de PERTY (1833), e nos trabalhos de SignORET (1853), MELICHAR (1931) e Young (1977). MELICHAR (1932) colocou a espécie em Cardioscarta (Melichar 1932) e METCALF (1965) em Poeciloscarta Stål, 1869. O exemplar tipo não foi examinado. Young (1977) não dispondo de material suficiente (apenas uma fêmea do Brasil) preferiu manter T. concinna como uma espécie de posição incerta. O estudo das genitálias masculina e feminina, aqui realizado, possibilitou incluir esta espécie em Scoposcartula. As manchas pretas da coroa e do pronoto são similares às de $S$. semipunctulata (Melichar, 1931). As tégminas são pretas em ambas as espécies e apresentam, na porção mediana, uma mancha amarelada. Entretanto, uma série de pontos castanho-amarelados ocorre na metade basal das tégminas de $S$. semipunctulata, mas não em $S$. concinna. O edeago de $S$. concinna é similar ao de $S$. inspergata (Signoret, 1855), enquanto que, a paráfise, em vez de simples, é bifurcada. Com relação à distribuição geográfica, as informações disponíveis na literatura indicam a presença de S. concinna na Bahia (MELICHAR 1931) e no Amazonas (PERTY 1833; BLANCHARD 1840).

\section{Scoposcartula flavovittata Mejdalani, 1992}

Figs $22-25$

Scoposcartula flavovittata Mejdalani, 1992: 231

Material examinado. BRASIL, Rio de Janeiro: Restinga de Marica, 1 fêmea 4-VI-1991, G. Mejdalani leg. (DZUP).

Descrição. Fêmea. Medidas (em milímetros): comprimento total: 12,72; comprimento mediano da cabeça: 0,88 ; distância transocular: 2,92 ; distância interocular: 1,92; comprimento mediano do pronoto: 1,88 ; distância entre os úmeros: 2,80; comprimento das tégminas: 10,32; largura máxima das tágminas: 2,36. Semelhante ao macho nos caracteres morfológicos externos e na coloração, conforme descrição da espécie por MEDJALANI (1992).

Genitália. Pigóforo tão longo quanto largo, com a margem apico-dorsal afilada, macrocerdas distribuidas ao longo da margem apical. VII esternito tão longo quanto largo, margem apical arredondada com uma leve projeção pontiaguda na região mediana; câmara genital com dois lóbulos arredondados e bem esclerotizada. Primeira valva do ovipositor com lóbulo arredondado na margem interna e sub-basal e uma projeção unciforme na base.

Discussão. Utilizando-se a chave de Young (1977), S. flavovittata não se enquadra em nenhuma das espécies incluídas. Essa espécie é relacionada à $S$. 
basimacula (Walker, 1851), com a qual compartilha a presença de uma faixa longitudinal amarela nas tégminas, estendendo-se da porção basal da célula discal interna à base da segunda célula apical (MEJDALANI 1992). Pode ser diferenciada pela presença de sete máculas amarelas na porção basal das tégminas, e por uma faixa amarela longitudinal adicional, estendendo-se da porção basal da célula discal externa à base da quarta célula apical.

Scoposcartula flavovittata ocorre em uma pequena área de mata de restinga, próximo do Rio de Janeiro. Essa mata, que sofre desmatamento para extração de madeira, apresenta uma vegetação de caráter psamófilo, entrando em sua constituição tanto elementos das dunas e moitas da restinga, como da Mata Atlântica de encosta (DORVILLÉ 1995). Coletas realizadas em várias outras localidades do Rio de Janeiro (incluindo áreas de Mata Atlântica e restinga) não revelaram a presença de S. flavovittata.

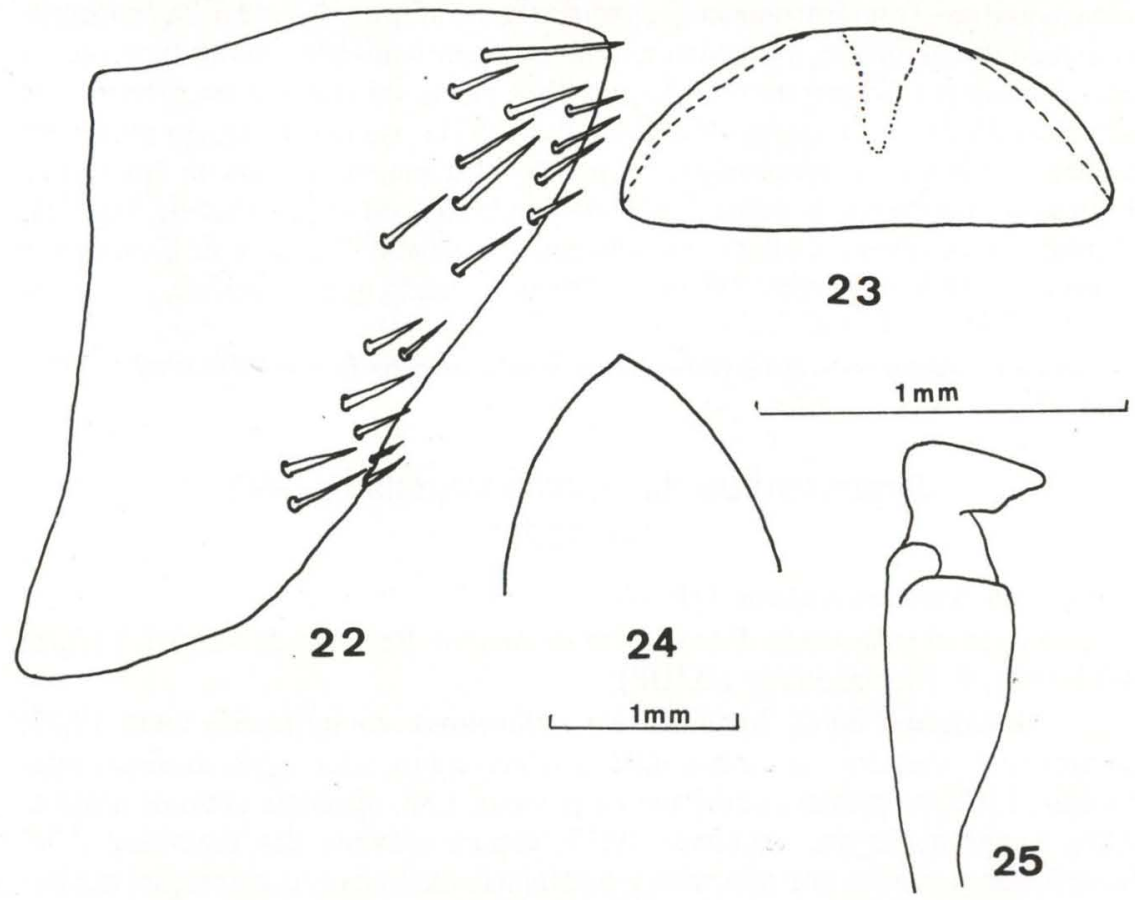

Figs 22-25. Scoposcartula flavovittata Medjalani, 1992. (22) Pigóforo da fêmea, em vista lateral; (23) câmara genital, em vista dorsal; (24) VII esternito, em vista ventral; (25) base da segunda valva do ovipositor, em vista ventral.

AGRADECIMENTOS. A J.L. Nessimian (UFRJ) e a A.C.R. Alves (UFRJ) que auxiliaram nas coletas de espécimes de S. tobiasi sp.n. na Serra da Mantiqueira. A Johann Becker (MNRJ), Ubirajara R. Martins de Souza (MZSP) e Mick Webb (BMNH) que gentilmente emprestaram espécimes da nova espécie para estudos. A J. A. P. Dutra (UFRJ) e E.R. da-SILVA (UNI-RIO) que revisaram o manuscrito. 


\section{REFERÊNCIAS BIBLIOGRÁFICAS}

BLANCHARD, É. 1840. Histoire naturelle des insects orthoptères, névroptères, hémiptères, hyménoptères, lépidoptères et diptères. Tome troisième. Paris, P. Duméril, 672p.

DORVILLÉ, L.F. 1995. Composição e aspectos da biologia da fauna de mosquitos

(Diptera, Culicidae) da Restinga de Barra de Maricá. Revta bras. Ent. 39 (1): 203-219.

MeJdalani, G.L.F. 1992. Uma nova espécie de Scoposcartula Young, 1977 do Sudeste do Brasil (Homoptera, Cicadellidae, Cicadellinae). Revta bras. Biol. 52 (2): 231-234.

Melichar, L. 1932. Monographie der Cicadellinen. IV. Annls hist. nat. Mus. natn. hung. 27: 285-328.

METCALF, Z.P. 1965. General Catalogue of the Homoptera. Fascicle VI,

Cicadelloidea. Part 1, Tettigellidae. Washington, Agricultural Research

Service, U.S. Department of Agriculture, 730p.

PERTY, J.A.M. 1830-1834. Delectus animalium articulatorum, quae in itinere per Brasiliam Annis MDCCCXVII-MDCCCXX jussu et auspicius Maximiliani Josephi I. Bavarie regis augustissimi peracto collegerunt Dr.

J. B. Spix et Dr. C. F. Ph. de Martius. Monachii, Impensis Editoris, III+224p. Signoret, V. 1853. Revue iconographique des Tettigonides. Annls Soc. ent. France, 1(3): 323-374.

WALKER, F. 1858. List of the specimens in the Collection of the British Museum. London, Supplement British Museum, 369p.

YounG, D.A. 1977. Taxonomic study of the Cicadellinae (Homoptera: Cicadellidae). Part 2. New World Cicadellini and the genus Cicadella. Bull. N. Carol. agric. Exp. Stn 239: VI+1135.

ZANOL, K.M.R. \& M. MeNEZES. 1982. Lista preliminar dos cicadelídeos (Homoptera, Cicadellidae) do Brasil. Iheringia Sér. Zool. 61: 9-65.

Recebido em 04.VII.1996; aceito em 20.XII.1996. 